\title{
ANDROGRAPHOLIDE, A DITERPENOID LACTONE COMPOUND OF Andrographis paniculata, BINDS TO LYS353 AND ASP38 IN THE PEPTIDASE DOMAIN OF HUMAN ANGIOTENSIN-CONVERTING ENZYME 2
}

\author{
S. Megantara, ${ }^{1}$ J. Levita, $^{2, \bowtie}$ S. Ibrahim ${ }^{3}$ and B. P. Nguyen ${ }^{4}$ \\ ${ }^{1}$ Department of Pharmaceutical Analysis and Medicinal Chemistry, Universitas Padjadjaran, \\ Sumedang-45363, (West Java) Indonesia \\ ${ }^{2}$ Department of Pharmacology and Clinical Pharmacy, Universitas Padjadjaran, \\ Sumedang-45363, (West Java) Indonesia \\ ${ }^{3}$ School of Pharmacy, Bandung Institute of Technology, Bandung-40116, (West Java) \\ Indonesia. \\ ${ }^{4}$ School of Mathematics and Statistics, Wellington Faculty of Science, Victoria University of \\ Wellington, Wellington, New Zealand

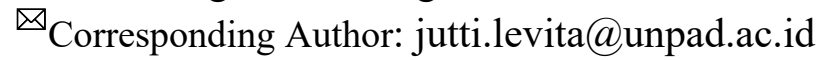

\begin{abstract}
The SARS-CoV-2 viruses use angiotensin-converting enzyme 2 (ACE2) to enter the human body. Infections are initiated by the binding of transmembrane spike (S) glycoprotein to the peptidase domain of human ACE2 (hACE2). A recent structural analysis reported the presence of two hotspots in hACE2 where the receptor-binding domain of the SARS-CoV-2 virus attached, namely hotspot-31 and hotspot-353. Our work studied the molecular interaction of diterpenoid lactones of Andrographis paniculata and the hydroxybenzylidene derivates of andrographolide with these hotspots in the peptidase domain of hACE2. The X-ray crystal structure of hACE2 was downloaded from RCSB Protein Data Bank (https:/www.rcsb.org/). The ligands were built using MarvinSketch of ChemAxon and were subjected to energy minimization using the MMFF94 forcefield partial charges in the LigandScout software. The energy-minimized ligands were docked to both hotspots of hACE2. The results indicated that of all test ligands, only andrographolide could occupy hotspot-353 by building hydrogen bonds with Lys353, Glu37, and Asp38, and possesses the best docking score $(-6.20 \mathrm{kcal} / \mathrm{mol})$. Thus, andrographolide might be able to prevent the fusion of SARS-CoV-2 to hACE2 by occupying the site where the viruses attach to.
\end{abstract}

Keywords: Andrographolide, Andrographis paniculata, COVID-19, SARS-CoV-2, Pneumonia

RASĀYAN J. Chem., Vol. 14, No.1, 2021

\section{INTRODUCTION}

SARS-CoV-2 (family: Coronaviridae, genus: Betacoronavirus), a novel virus that emerged from Wuhan, China, is responsible for a recent outbreak of deadly respiratory illness. The pneumonia-related disease caused by this virus has been defined as coronavirus disease-19 or COVID-19. This virus, which causes similar symptoms in humans to those caused by SARS coronavirus (SARS-CoV), has spread to more than 170 countries with a total of 95,003,533 confirmed-cases around the world with 2,029,938 global deaths (data taken from John Hopkins CSSE (https://coronavirus.jhu.edu/map.html per 18th January 2021). This virus uses angiotensin-converting enzyme 2 (ACE2), to enter the human body and the cellular protease TMPRSS2 for its S-protein priming. ${ }^{1}$ Infection is initiated by the binding of transmembrane spike (S) glycoprotein to host receptors and interacts with the peptidase domain of hACE2 (Kd of $\sim 15 \mathrm{nM}$ ). ${ }^{2}$ The human coronaviruses evolved similar strategies to engage sialoglycans at the surface of target cells. ${ }^{3}$ Furthermore, a previous study by Wan and colleagues who analyzed the potential receptor usage by the 2019 SARS-CoV-2, based on the rich knowledge about SARS-CoV, specified that: (1) the sequence of SARS-CoV-2 receptor-binding domain (RBD), including its receptor-binding motif that directly contacts ACE2, is similar to that of SARS-CoV. This fact strongly suggesting that SARS-CoV-2 uses ACE2 as its receptor; (2) several important amino acid residues in SARS-CoV-2 receptor-binding motif (Gln493 in particular) provide favorable interactions with 
hACE2, consistent with SARS-CoV-2's capacity for human cell infection; (3) other critical amino acid residues in SARS-CoV-2 receptor-binding motif (i.e. Asn501) are compatible with the binding domain of hACE2. This means that SARS-CoV-2 acquires a specific capacity for human-to-human transmission; (4) a bat origin of SARS-CoV-2 also recognizes ACE2 from a diversity of animal species (except mice and rats), which implicates that these animals are possible as intermediate hosts for SARSCoV-2 infections. ${ }^{4}$ The residue 479 in of SARS-CoV-2 RBD optimal for binding binds to hotspot-31 of hACE2 which is located near a salt bridge between Lys31 and Glu35, buried in a hydrophobic environment of the peptidase domain of ACE2. Another important site is hotspot-353, which consists of a salt bridge between Lys353 and Asp38 also buried in a hydrophobic pocket. Therefore, the key amino acid residues in the peptidase domain of hACE2 where the SARS-CoV-2 might bind are Gln24, Asp30, Lys31, His34, Glu35, Asp38, Tyr41, Gln42, Met82, Lys353, Arg357.,5

Recent studies reported the use of antimalarial drugs, e.g. chloroquine phosphate, to treat patients diagnosed with COVID-19 associated-pneumonia. This drug has been recommended to be included in the Guidelines for the Prevention, Diagnosis, and Treatment of Pneumonia Caused by COVID-19. ${ }^{6}$ Remdesivir and chloroquine were confirmed to have strong inhibitory activity on viral infection at $\mathrm{EC}_{50}=0.77 \mu \mathrm{M}$ and $\mathrm{EC}_{50}=1.13 \mu \mathrm{M}$, respectively. ${ }^{7}$ A previous in silico study reported that the key binding of chloroquine, hydroxychloroquine, and quinine with Lys353 in hACE2 might correlate with the inhibitory activity of drugs on viral infection. ${ }^{8}$ Andrographolide, a major diterpenoid lactone compound of Andrographis paniculata (Burm. f.) Nees has been reported to possess antimalarial, antiHIV in vitro by inhibiting gp120-mediated cell fusion of HL2/3 cells with TZM-bl cells, and antiHerpes simplex virus activities..$^{9-11}$ On the other hand, another in silico study of Megantara and coworkers revealed that andrographolide (Fig.-1) and its synthesized-hydroxybenzylidene derivates (Fig.1) interacted with important aspartic acid residues in the binding pocket of plasmepsin I, II, and IV, thus these compounds could be developed as protease inhibitors for antimalarial drug discovery. ${ }^{12}$ However, it is interesting to exploit the possibility of diterpenoid lactones of A. paniculata and the hydroxybenzylidene derivates of andrographolide by studying their interaction with hotspot- 31 and hotspot-353 in the peptidase domain of hACE2.

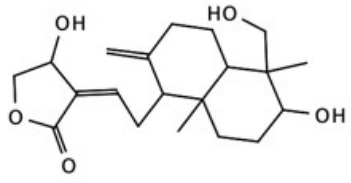

Andrographolide

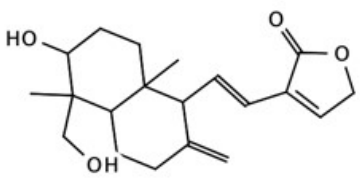

14-Deoxy-11,12-didehydroandrographolide

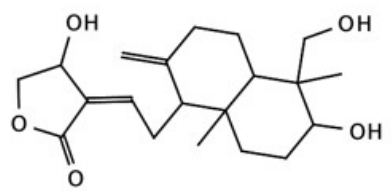

Isoandrographolide

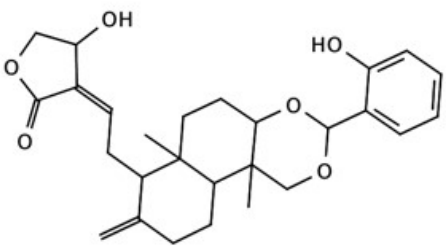

3,19-2-hydroxybenzylidene andrographolide

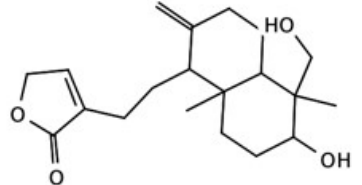

14-Deoxyandrographolide

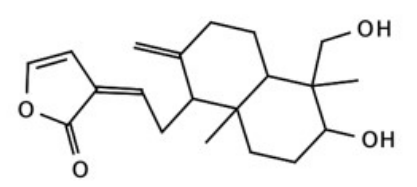

14-Deoxy-14,15-didehydroandrographolide

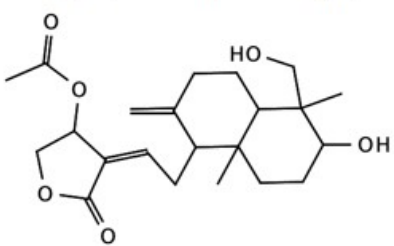

14-Acetylandrographolide

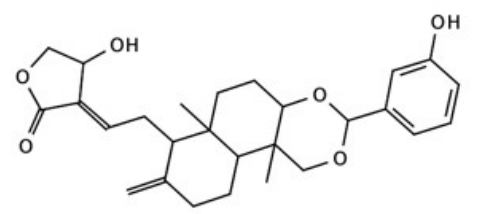

3,19-3-hydroxybenzylidene andrographolide

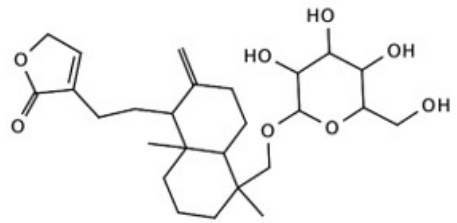

Neoandrographolide
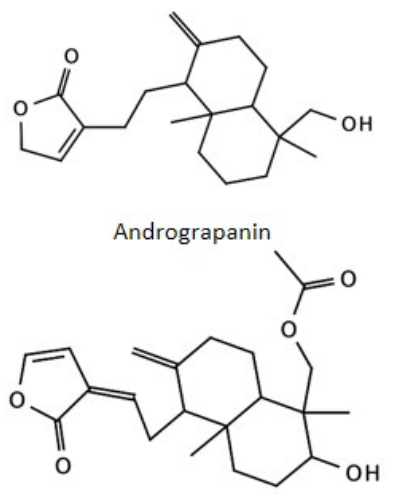

19-O-acetylanhydroandrographolide

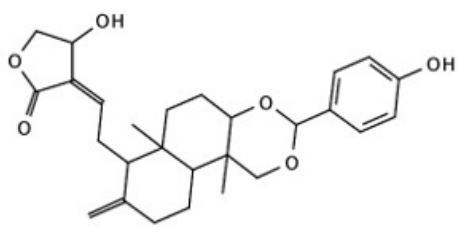

3,19-4-hydroxybenzylidene andrographolide

Fig.-1: 2D Molecular Structure of Diterpenoid Lactone Compounds in A. paniculata and Synthesizedhydroxybenzylidene Derivates. ${ }^{12,13}$ Structures of Ligand were built using MarvinSketch 20.10 of ChemAxon. ANDROGRAPHOLIDE 


\section{Hardware and Software}

\section{EXPERIMENTAL}

The hardware used was MacBook Pro (13-inch, Mid 2012) embedded with macOS Mojave 10.14.6, 2.5 GHz Intel Core i5 processor, 16 GB $1600 \mathrm{MHz}$ DDR3, and Intel HD Graphics $40001536 \mathrm{MB}$. Softwares used were MarvinSketch of ChemAxon 17.11.0 (Academic License), LigandScout 4.1.4 (Universitas Padjadjaran License), AutoDock 1.5.6, AutoDock Vina 1.1, and Discovery Studio Visualizer (Freeware).

\section{Preparation of Ligands and Molecular Docking}

The 2D structure of all test ligands, e.g. andrographolide, 14-deoxyandrographolide, neoandrographolide, 14-deoxy-11,12-didehydroandrographolide, 14-deoxy-14,15didehydroandrographolide, andrograpanin, isoandrographolide, 14-acetylandrographolide, 19-oacetylanhydroandrographolide, and the three hydroxybenzylidene derivates were built using MarvinSketch of ChemAxon. The ligands were subsequently converted to a 3D structure and then subjected to energy minimization using the MMFF94 forcefield partial charges in LigandScout. Geometry optimization was performed using MMFF94, which is intended to produce accurate geometric structures. ${ }^{14}$ Physicochemical properties were also predicted using LigandScout.

Molecular docking was carried out for all the test compounds towards hotspot-31 and hotspot-353 in the peptidase domain of hACE2 by employing AutoDock Vina embedded in the LigandScout. The flexibility of hACE2 was regulated by setting the scaling factor for the nonpolar atoms to 0.8 . All other parameters were fixed at the default condition. The binding affinity of the hACE2/ligand complexes was expressed in terms of docking scores.

\section{RESULTS AND DISCUSSION}

The LBD of hACE2, that is located at the extracellular peptidase domain, is recognized by the RBD of the SARS-CoV-2. ${ }^{5}$ The coordinate of hACE2 LBD (Fig.-2) are $\mathrm{x}=85, \mathrm{y}=-10, \mathrm{z}=180$ (grid box dimension: $x=75$ points, $y=75$ points, $z=75$ points, spacing: $0.375 \AA$ ). It reveals the presence of $A s n 33 A$, Glu37A, Asp38A, Leu39A, Tyr41A, Gln42A, Lys353A, Arg357A. This location corresponds to that of Yan et al. (2020) and Wan et al. (2020) describing that the peptidase domain of hACE2 where the SARS-CoV-2 binds comprises of Gln24, Asp30, Lys31, His34, Glu35, Asp38, Tyr41, Gln42, Met82, Lys353, Arg357.,

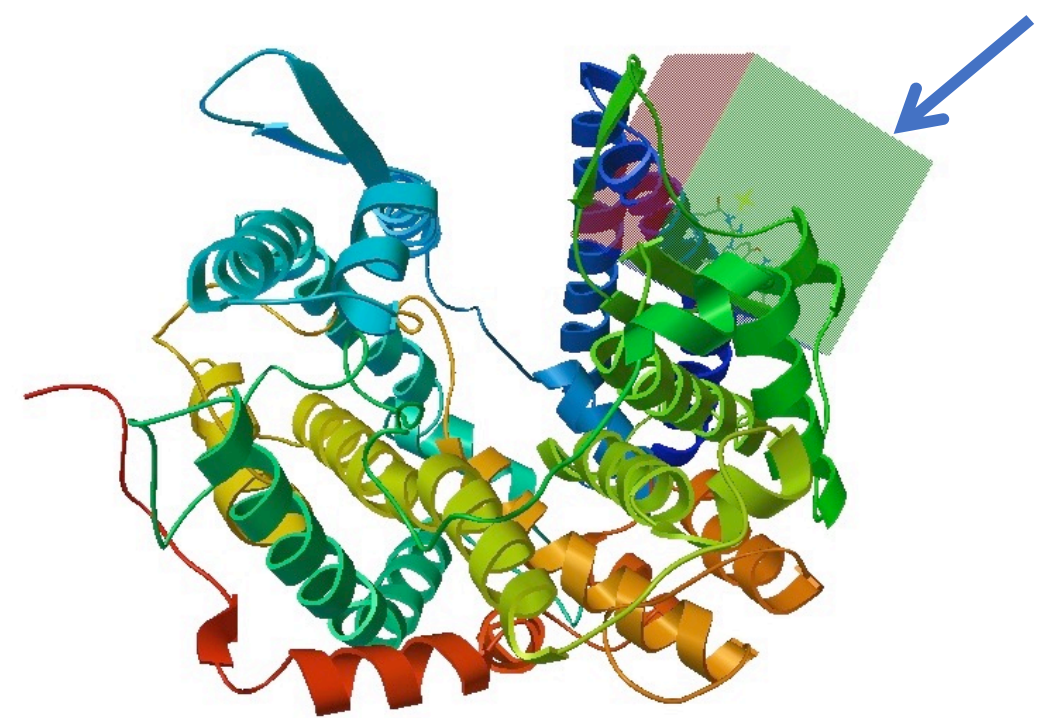

Fig.-2: The Hotspots of hACE2 are visualized as a Green-magenta Box (indicated by a bold arrow).

It lies at coordinates: $\mathrm{x}=85, \mathrm{y}=-10, \mathrm{z}=180$. The dimension of the grid box are $\mathrm{x}=75$ points, $\mathrm{y}=75$ points, $\mathrm{z}$ $=75$ points, spacing $0.375 \AA$, centered on important amino acid residues.

The physicochemical properties of the ligands are presented in Table-1. 
RASĀYAN J. Chem.

Vol. 14 | No. 1 |241-247| January - March | 2021

Table-1: Physicochemical Properties of Andrographolide, 14-Deoxyandrographolide, Neoandrographolide, $14-$

Deoxy-11,12-didehydroandrographolide, 14-Deoxy-14,15-didehydroandrographolide, Andrograpanin,

Isoandrographolide, 14-Acetylandrographolide, 19-o-Acetylanhydroandrographolide, 3,19-2-

Hydroxybenzylidene andrographolide, 3,19-3-Hydroxybenzylidene andrographolide, and 3,19-4Hydroxybenzylidene andrographolide.

\begin{tabular}{|c|c|c|c|c|c|}
\hline Name of Compound & $\begin{array}{l}\text { Formula } \\
\text { (MW) }\end{array}$ & $\begin{array}{c}\text { Aromatic } \\
\text { Atoms } \\
\text { (rotatable } \\
\text { bonds) }\end{array}$ & cLogP & $\begin{array}{l}\text { Hydrogen } \\
\text { Bond } \\
\text { Acceptor } \\
\text { (HBA) }\end{array}$ & $\begin{array}{l}\text { Hydrogen } \\
\text { Bond Donor } \\
\text { (HBD) }\end{array}$ \\
\hline Andrographolide & $\begin{array}{l}\mathrm{C}_{20} \mathrm{H}_{30} \mathrm{O}_{5} \\
(350.455)\end{array}$ & $0(8)$ & 1.963 & 4 & 3 \\
\hline 14-Deoxyandrographolide & $\begin{array}{l}\mathrm{C}_{20} \mathrm{H}_{30} \mathrm{O}_{4} \\
(334.456) \\
\end{array}$ & $5(8)$ & 3.079 & 1 & 0 \\
\hline Neoandrographolide & $\begin{array}{l}\mathrm{C}_{27} \mathrm{H}_{34} \mathrm{O}_{6} \\
(454.563)\end{array}$ & $6(7)$ & 3.856 & 5 & 2 \\
\hline $\begin{array}{c}\text { 14-Deoxy-11,12- } \\
\text { didehydroandrographolide }\end{array}$ & $\begin{array}{l}\mathrm{C}_{20} \mathrm{H}_{28} \mathrm{O}_{4} \\
(332.440)\end{array}$ & $5(7)$ & 3.160 & 1 & 0 \\
\hline $\begin{array}{c}\text { 14-Deoxy-14,15- } \\
\text { didehydroandrographolide }\end{array}$ & $\begin{array}{l}\mathrm{C}_{20} \mathrm{H}_{28} \mathrm{O}_{4} \\
(332.440)\end{array}$ & $5(7)$ & 2.271 & 1 & 0 \\
\hline Andrograpanin & $\begin{array}{l}\mathrm{C}_{20} \mathrm{H}_{30} \mathrm{O}_{3} \\
(318.457)\end{array}$ & $5(7)$ & 2.271 & 1 & 0 \\
\hline Isoandrographolide & $\begin{array}{l}\mathrm{C}_{20} \mathrm{H}_{30} \mathrm{O}_{5} \\
(350.455) \\
\end{array}$ & $0(8)$ & 1.963 & 1 & 1 \\
\hline 14-Acetylandrographolide & $\begin{array}{l}\mathrm{C}_{22} \mathrm{H}_{32} \mathrm{O}_{6} \\
(392.492)\end{array}$ & $0(10)$ & 2.533 & 1 & 2 \\
\hline 19-O-acetylanhydroandrographolide & $\begin{array}{l}\mathrm{C}_{22} \mathrm{H}_{30} \mathrm{O} 5 \\
(374.477)\end{array}$ & $5(9)$ & 2.842 & 1 & 0 \\
\hline $\begin{array}{l}\text { 3,19-2-hydroxybenzylidene } \\
\text { andrographolide }\end{array}$ & $\begin{array}{l}\mathrm{C}_{27} \mathrm{H}_{34} \mathrm{O}_{6} \\
(454.563)\end{array}$ & $6(7)$ & 3.856 & 5 & 2 \\
\hline $\begin{array}{c}\text { 3,19-3-hydroxybenzylidene } \\
\text { andrographolide }\end{array}$ & $\begin{array}{l}\mathrm{C}_{27} \mathrm{H}_{34} \mathrm{O}_{6} \\
(454.563) \\
\end{array}$ & $6(7)$ & 3.856 & 5 & 2 \\
\hline $\begin{array}{l}\text { 3,19-4-hydroxybenzylidene } \\
\text { andrographolide }\end{array}$ & $\begin{array}{l}\mathrm{C}_{27} \mathrm{H}_{34} \mathrm{O}_{6} \\
(454.563)\end{array}$ & $6(7)$ & 3.856 & 5 & 2 \\
\hline
\end{tabular}

Of all ligands, andrographolide and its isomer, isoandrographolide, are the most hydrophilic and flexible compounds. The flexibility of a ligand is considered important due to its influence on the binding of the ligand to its receptor. According to Koshland (1958) as cited by Lexa and Carlson, when a ligand approaches a receptor to build the ligand-receptor complex, the receptor will eventually reshape its conformation to provide accessibility for the ligand-binding. ${ }^{15}$

The binding mode and affinity of the ligands in hotspot-353 of the peptidase domain of hACE2 are presented in Table-2. The results indicate that all ligands could only bind to hotspot-353, omit hotspot31, and interestingly, only andrographolide interacts with the key amino acid residues: Lys353 and Asp38. The other diterpenoid lactones, with the exception: neoandrographolide and 3,19-3hidroxybenzylidene andrographolide, interact with Lys353 only. The derivate of andrographolide, namely 3,19-2-hidroxybenzylidene-andrographolide, interacts with Asp38.

Table-2: The Binding Mode and Affinity of the Ligands in Hotspot-353 of the Peptidase Domain of ACE2

\begin{tabular}{|c|c|c|c|c|}
\hline No. & Ligand & $\begin{array}{l}\text { Binding Affinity } \\
\text { in term of } \\
\text { Docking Score } \\
(\mathrm{kcal} / \mathrm{mol})\end{array}$ & $\begin{array}{l}\text { Amino Acid Residues } \\
\text { Involved in the } \\
\text { Interaction }\end{array}$ & $\begin{array}{c}\text { Binding Mode } \\
\text { (Type of Interaction) }\end{array}$ \\
\hline \multirow{3}{*}{1.} & \multirow{3}{*}{ Andrographolide } & \multirow{3}{*}{-6.20} & Glu37 & Hydrogen Bond \\
\hline & & & Asp38** & Hydrogen Bond \\
\hline & & & Lys353** & Hydrogen Bond \\
\hline 2. & 14-Deoxyandrographolide & -4.47 & Lys353** & Hydrogen Bond \\
\hline \multirow{5}{*}{3.} & \multirow{5}{*}{ Neoandrographolide } & \multirow{5}{*}{-6.47} & Asn33 & Hydrogen Bond \\
\hline & & & His34* & Hydrogen Bond \\
\hline & & & Lys403 & Hydrogen Bond \\
\hline & & & Val417 & Hydrophobic \\
\hline & & & Gly496 & Hydrogen Bond \\
\hline
\end{tabular}


RASĀYAN J. Chem.

Vol. 14 | No. 1 |241-247| January - March | 2021

\begin{tabular}{|c|c|c|c|c|}
\hline & & & Tyr505 & Hydrogen Bond \\
\hline 4. & $\begin{array}{c}\text { 14-Deoxy-11,12- } \\
\text { didehydroandrographolide }\end{array}$ & -4.29 & Lys353** & Hydrogen Bond \\
\hline 5. & $\begin{array}{c}\text { 14-Deoxy-14,15- } \\
\text { didehydroandrographolide }\end{array}$ & -4.94 & Lys353** & Hydrogen Bond \\
\hline 6. & Andrograpanin & -2.82 & Lys353** & Hydrogen Bond \\
\hline \multirow{2}{*}{7.} & \multirow{2}{*}{ Isoandrographolide } & \multirow{2}{*}{-3.49} & His34 & Hydrogen Bond \\
\hline & & & Lys353** & Hydrogen Bond \\
\hline \multirow{2}{*}{8.} & \multirow{2}{*}{ 14-Acetylandrographolide } & \multirow{2}{*}{-4.15} & Asn33 & Hydrogen Bond \\
\hline & & & Lys353** & Hydrogen Bond \\
\hline 9. & $\begin{array}{c}\text { 19- } O \text {-acetyl } \\
\text { anhydroandrographolide }\end{array}$ & -4.21 & Lys $353 * *$ & Hydrogen Bond \\
\hline \multirow{2}{*}{10.} & \multirow{2}{*}{$\begin{array}{l}\text { 3,19-2-hidroxybenzylidene } \\
\text { andrographolide }\end{array}$} & \multirow{2}{*}{-5.85} & Asn33 & Hydrogen Bond \\
\hline & & & Asp38** & Hydrogen Bond \\
\hline \multirow{3}{*}{11.} & \multirow{3}{*}{$\begin{array}{l}\text { 3,19-3-hidroxybenzylidene } \\
\text { andrographolide }\end{array}$} & \multirow{3}{*}{-6.07} & Glu35* & Hydrogen Bond \\
\hline & & & Glu37 & Hydrogen Bond \\
\hline & & & Leu39 & Hydrophobic \\
\hline \multirow{2}{*}{12.} & \multirow{2}{*}{$\begin{array}{l}\text { 3,19-4-hidroxybenzylidene } \\
\text { andrographolide }\end{array}$} & \multirow{2}{*}{-5.63} & Glu37 & Hydrogen Bond \\
\hline & & & Lys353** & $\mathrm{Pi}$ - Pi Stacking \\
\hline
\end{tabular}

* indicates the key amino acid in hotspot-31; ** indicates the key amino acid in hotspot-353

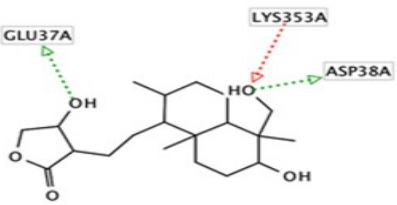

Andrographolide

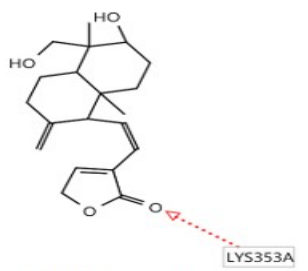

14-Deoxy-11,12-didehydroandrographolide

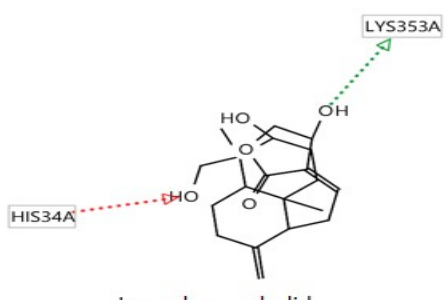

Isoandrographolide

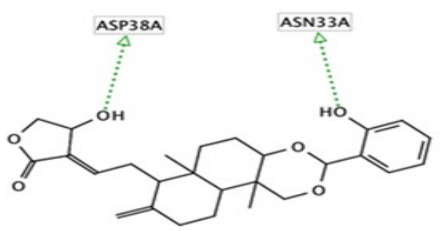

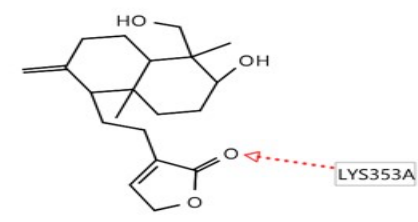

14-Deoxyandrographolide

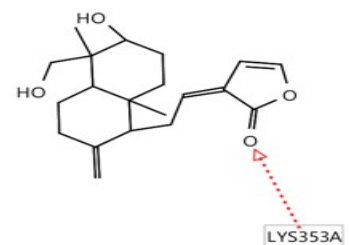

14-Deoxy-14,15-didehydroandrographolide LYS353A.

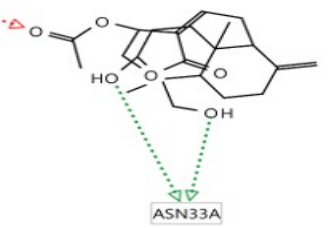

14-Acetylandrographolide

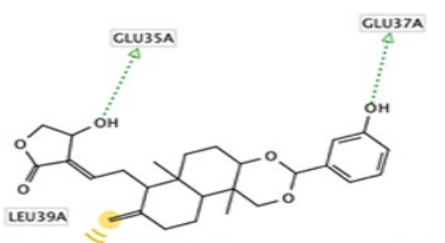

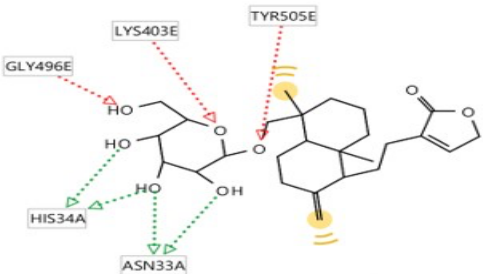

Neoandrographolide VAL417E

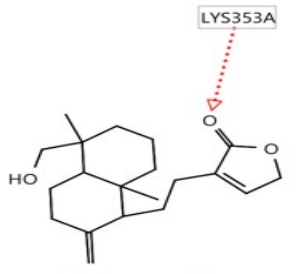

Andrograpanin

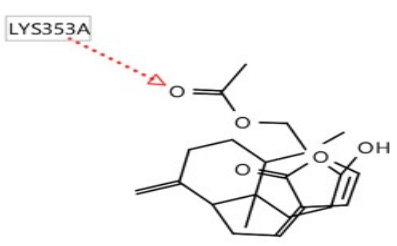

19-O-acetylanhydroandrographolide

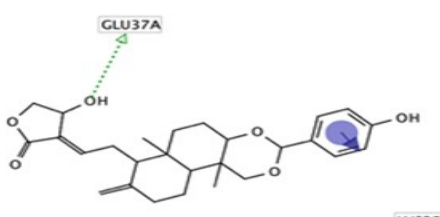

Lrs353A

3,19-2-hydroxybenzylidene andrographolide

3,19-3-hydroxybenzylidene andrographolide

3,19-4-hydroxybenzylidene andrographolide

Fig.-3: The Binding Mode of Andrographolide, 14-Deoxyandrographolide, Neoandrographolide, 14-Deoxy-

11,12-didehydroandrographolide, 14-Deoxy-14,15-didehydroandrographolide, Andrograpanin,

Isoandrographolide, 14-Acetylandrographolide, 19-o-Acetylanhydroandrographolide, 3,19-2-

Hydroxybenzylidene andrographolide, 3,19-3-Hydroxybenzylidene andrographolide, and 3,19-4-

Hydroxybenzylidene andrographolide.with Amino Acid Residues in Hotspot-353 of the Peptidase Domain of

hACE2. The hydrogen bond is shown as a dotted-arrow (HBA: red; HBD: green), while the hydrophobic

interaction is visualized by the yellow highlight and pi-pi interaction is visualized by the violet circle. 
Andrographolide (depicted in Fig.-3 and Fig.-4) indicates the best docking pose. The hydroxyl group of andrographolide (hydrogen bond donor) interacts with Lys353 and Asp38 in the hotspot-353 of the peptidase domain of hACE2 (Fig.-3). Moreover, neoandrographolide and the two hydroxybenzylideneandrographolides, due to their bulky structures, occupy a different binding site.

The hotspot-353 consists of a salt bridge between Lys353 and Asp38 (a salt bridge is a combination of a hydrogen bond and an electrostatic interaction, depicted in Fig.-5). Lys353 is a crucial amino acid residue in hACE2 due to its role as the site for the binding of SARS-CoV-2's Asn501. Thus, Lys353 and Asp38 in hACE2 are critical for the SARS-CoV-2 RBD/hACE2 interactions. ${ }^{4,16}$ The binding mode, in terms of the hydrogen bonds, ${ }^{17}$ of andrographolide and amino acid residues in hotspot-353, is important as it visualizes that this diterpenoid lactone competitively occupies hotspot-353 in the peptidase domain of hACE2, thus leaves the Asn501 of SARS-CoV-2 with no empty site to bind to. Andrographolide is always interesting to be explored in its various pharmacological activities. A recent study reported that this compound strongly inhibited the viability of HeLa cells at low concentration. ${ }^{18}$

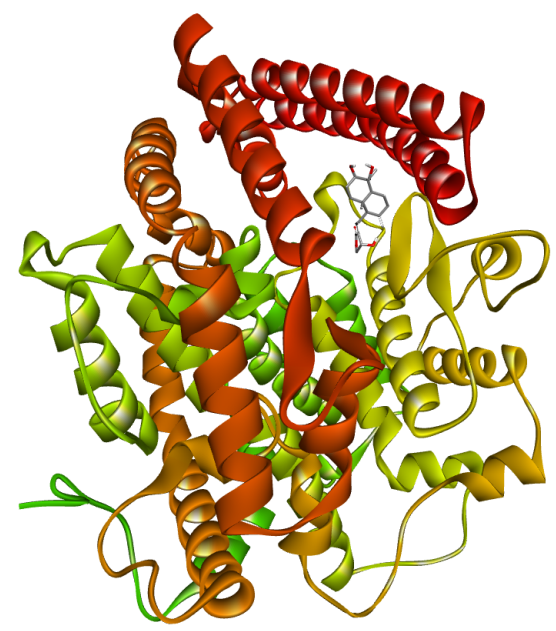

Fig.-4: The 3D Docking Pose of Andrographolide in Hotspot-353

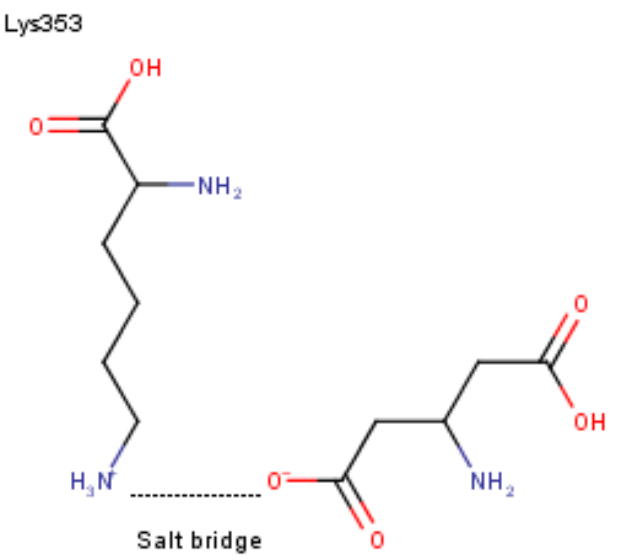

Asp38

Fig-5: The Proposed Salt Bridge between Lys353 and Asp38 in Hotspot-353. A hydrogen bond is built between the hydrogen atom of Lys353's amine with the oxygen atom of Asp38's carboxylate anion. Electrostatic interaction is formed between the $-\mathrm{NH}^{+}$cation of Lys353 with the carboxylate anion of Asp38. The chemical structures were drawn using MarvinSketch of ChemAxon

\section{CONCLUSION}

Discovering the inhibitor of SARS-CoV-2 fusion to the hACE2 (human angiotensin-converting enzyme 2 ) is a challenging task due to the exponential outbreak of the SARS-CoV-2 in more than 170 countries. Importantly, a recent structural analysis had reported the presence of two hotspots in hACE2 where the RBD of the SARS-CoV-2 virus attaches, namely hotspot-31 and hotspot-353. Of our test compounds, andrographolide, a major diterpenoid lactone of Andrographis paniculata, was confirmed to effectively prevent the fusion of SARS-CoV-2 to hACE2 by breaking the salt bridge in hotspot-353 and occupying 
the site where the virus binds (Lys353 and Asp38). This study will be beneficial for plant-based drug discovery, particularly the inhibitor of SARS-CoV-2 fusion to the hACE2. However, in vitro and in vivo explorations are still needed to uncover the interesting activity of this diterpenoid lactone.

\section{ACKNOWLEDGEMENT}

The authors thank (1) the Rector of Universitas Padjadjaran for funding this project via the DRPM internal grant of RDPD 2020 and (2) the Center for Computational Research, Faculty of Pharmacy, Universitas Padjadjaran for granting permission to use the Discovery Studio Program.

\section{REFERENCES}

1. M. Hoffmann, H. Kleine-Weber, S. Schroeder, N. Krüger, T. Herrler, S. Erichsen, T. S. Schiergens, G. Herrler, N. H. Wu, A. Nitsche, M. A. Müller, C. Drosten and S. Pöhlmann, Cell, 181(2), 271(2020), DOI:10.1016\%2Fj.cell.2020.02.052

2. D. Wrapp, N. Wang, K. S. Corbett, J. A. Goldsmith, C. L. Hsieh, O. Abiona, B. S. Graham and J. S. McLellan, Science, 367(6483), 1260(2020), DOI:10.1126/science.abb2507

3. M. A. Tortorici, A. C. Walls, Y. Lang, C. Wang, Z. Li, D. Koerhuis, G. J. Boons, B. J. Bosch, F. A. Rey, R. J. de Groot and D. Veesler, Nature Structural \& Molecular Biology, 26(6), 481(2019). DOI:10.1038/s41594-019-0233-y

4. Y. Wan, J. Shang, R. Graham, R. S. Baric and F. Li, Journal of Virology, 94(7), e00127(2020). DOI:10.1128/JVI.00127-20

5. R. Yan, Y. Zhang, Y. Li, L. Xia, Y. Guo and Q. Zhou, Science, 367(6485), 1444(2020), DOI:10.1126/science.abb2762

6. J. Gao, Z. Tian and X. Yang, BioScience Trends, 14(1), 72(2020), DOI:10.5582/bst.2020.01047

7. M. Wang, R. Cao, L. Zhang, X. Yang, J. Liu, M. Xu, Z. Shi, Z. Hu, W. Zhong and G. Xiao, Cell Research, 30(3), 269(2020), DOI:10.1038/s41422-020-0282-0

8. K. Lestari, T. Sitorus, Instiaty, S. Megantara and J. Levita, Journal Of Advanced Pharmacy Education and Research, 10(2), 1(2020).

9. K. Mishra, A. P. Dash and N. Dey, Journal of Tropical Medicine, 2011, (2011), DOI: $10.1155 / 2011 / 579518$

10. M. M. Uttekar, T. Das, R. S. Pawar, B. Bhandari, V. Menon, Nutan, S. K. Gupta and S. V. Bhat, European Journal of Medicinal Chemistry, 56, 368(2012), DOI:10.1016/j.ejmech.2012.07.030

11. C. Wiart, K. Kumar, M. Y. Yusof, H. Hamimah, Z. M. Fauzi and M. Sulaiman, Phytotherapy Research, 19(12), 1069(2005), DOI:doi.org/10.1002/ptr.1765

12. S. Megantara, M. I. Iwo, J. Levita and S. Ibrahim, Journal of Applied Pharmaceutical Science, 6(1): 125(2017), DOI:10.7324/JAPS.2016.600120

13. W. W. Chao and B. F. Lin, Chinese Medicine, 5, 17(2010), DOI:10.1186/1749-8546-5-17

14. P. Tosco, N. Stiefl and G. Landrum, Journal of Cheminformatics, 6(37),1(2014), DOI:10.1186/s13321-014-0037-3

15. K. W. Lexa and H. A. Carlson, Quarterly Reviews of Biophysics, 45(3),301(2012), DOI:10.1017/s0033583512000066

16. K. Wu, L. Chen, G. Peng, W. Zhou, C. A. Pennell, L. M. Mansky, R. J. Geraghty and F. Li, Journal of Virology, 85(11), (2011), DOI:10.1128/JVI.02274-10

17. S. Megantara, M. Mutakin, E. Halimah, E. Febrina and J. Levita, Rasayan Journal of Chemistry, 13(3), 1321(2020), DOI:10.31788/RJC.2020.1335766

18. L.Anwar, A. Santoni, D. P. Putra and M. Efdi, Rasayan Journal of Chemistry, 12(3), 1641(2019), DOI:10.31788/RJC.2019.1235025

[RJC-6070/2020] 